\title{
Antimicrobial susceptibility profiles of human and piglet Clostridium difficile PCR-ribotype 078
}

\author{
Elisabeth C Keessen², Marjolein PM Hensgens ${ }^{1}$, Patrizia Spigaglia ${ }^{3}$, Fabrizio Barbanti ${ }^{3}$, Ingrid MJG Sanders',
} Ed J Kuijper ${ }^{1 *}$ and Len JA Lipman²

\begin{abstract}
In the last decade, outbreaks of nosocomial Clostridium difficile infections (CDI) occurred worldwide. A new emerging type, PCR-ribotype 027, was the associated pathogen. Antimicrobial susceptibility profiles of this type were extensively investigated and used to partly explain its spread. In Europe, the incidence of $C$. difficile PCR-ribotype 078 recently increased in humans and piglets. Using recommendations of the European Committee on Antimicrobial Susceptibility Testing (EUCAST) and the Clinical and Laboratory Standards Institute (CLSI) we studied the antimicrobial susceptibility to eight antimicrobials, mechanisms of resistance and the relation with previously prescribed antimicrobials in human $(n=49)$ and porcine $(n=50)$ type 078 isolates. Human and porcine type 078 isolates showed similar antimicrobial susceptibility patterns for the antimicrobials tested. In total, $37 \%$ of the isolates were resistant to four or more antimicrobial agents. The majority of the human and porcine isolates were susceptible to amoxicillin (100\%), tetracycline (100\%) and clindamycin (96\%) and resistant to ciprofloxacin (96\%). More variation was found for resistance patterns to erythromycin (76\% in human and 59\% in porcine isolates), imipenem (29\% in human and $50 \%$ in porcine isolates) and moxifloxacin (16\% for both human and porcine isolates). MIC values of cefuroxim were high (MICs $>256 \mathrm{mg} / \mathrm{L}$ ) in $96 \%$ of the isolates. Resistance to moxifloxacin and clindamycin was associated with a gyr(A) mutation and the presence of the erm(B) gene, respectively. A large proportion (96\%) of the erythromycin resistant isolates did not carry the erm(B) gene. The use of ciprofloxacin (humans) and enrofloxacin (pigs) was significantly associated with isolation of moxifloxacin resistant isolates. Increased fluoroquinolone use could have contributed to the spread of C. difficile type 078.
\end{abstract}

\section{Introduction}

Clostridium difficile is a ubiquitous organism that recently emerged in both humans and animals. In humans, C. difficile is the leading cause of nosocomial diarrhea. In the last decade incidences of $C$. difficile infections (CDI) increased, which was partly explained by the emergence of the hypervirulent $C$. difficile PCR-ribotype 027 [1-3]. Since 2006, the incidence of nosocomial CDI is constant in The Netherlands, encompassing a decrease of CDI caused by type 027 [4]. Meanwhile, C. difficile PCRribotype 078 increased and it became the third most commonly type found in human infections in The Netherlands and Europe [4-6]. Type 078 causes severe diarrhea in $40 \%$ of the patients and is associated with CDI-related mortality in 4 percent after 30 days [6].

\footnotetext{
* Correspondence: ejkuijper@gmail.com

'Department of Medical Microbiology, Leiden University Medical Center, PO Box 9600, Leiden 2300 RC, the Netherlands

Full list of author information is available at the end of the article
}

Patients infected with type 078 are younger and the disease more frequently occurs outside healthcare facilities [6]. Besides a high prevalence in human CDI, type 078 is the main cause for CDI in neonatal piglets [7-9]. In the United States, CDI is even the most commonly diagnosed cause of enteritis in neonatal piglets [10]. Morbidity in an infected farrowing facility is on average $2 / 3$ of litters and $1 / 3$ of individual piglets [11], but may be as high as $97-100 \%$ [10]. Mortality due to C. difficile is usually low, nonetheless, outbreaks with mortality rates of $16 \%$ have been reported [12].

In humans, the use of antimicrobials, in particular cephalosporins, clindamycin and fluoroquinolones, is a major risk factor for CDI [13]. Resistance to newer fluoroquinolones was used to partly explain the emergence of type 027 in healthcare centers [1-3]. For type 078, especially porcine type 078 , antimicrobial susceptibility profiles are less extensively investigated. Therefore,
C Biomed Central

(C) 2013 Keessen et al.; licensee BioMed Central Ltd. This is an Open Access article distributed under the terms of the Creative Commons Attribution License (http://creativecommons.org/licenses/by/2.0), which permits unrestricted use, distribution, and reproduction in any medium, provided the original work is properly cited. 


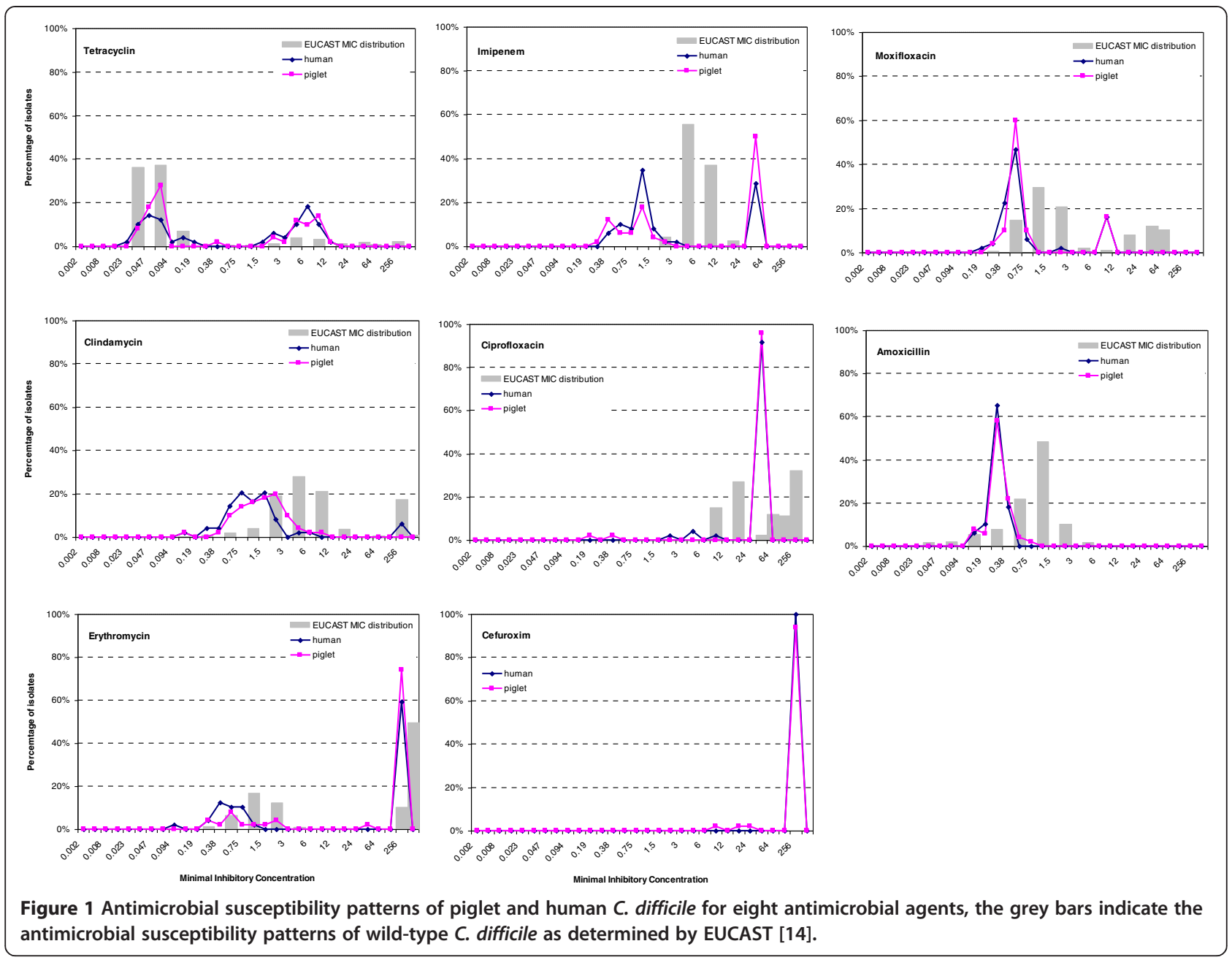

the goal of this study is to analyze susceptibility profiles and mechanisms of resistance for $C$. difficile type 078 isolates of human and porcine origin and to assess if a specific resistance is related to prior antimicrobial exposure.

\section{Materials and methods}

\section{Sample selection}

Between April 2009 and January 2010 we visited 25 Dutch pig breeder farms. Twenty-two farms had problems with recurrent diarrhea in neonatal piglets, three

Table 1 Antibiotic resistance against eight antimicrobial agents, stratified for origin of the sample

\begin{tabular}{|c|c|c|c|c|c|c|c|}
\hline \multirow{2}{*}{$\begin{array}{c}\text { Antibiotic } \\
\text { agent }\end{array}$} & \multicolumn{3}{|c|}{ MIC 90 (mg/L) } & \multicolumn{4}{|c|}{ Resistant isolates according to $\mathrm{CLSI}^{\mathrm{b}}$ (\%) } \\
\hline & Human $n=49$ & Pig $n=50$ & $\operatorname{ECOFF}^{\mathrm{a}}(\mathrm{mg} / \mathrm{L})$ & Breakpoint (mg/L) & Human $n=49$ & Pig $n=50$ & Difference $p$-value \\
\hline Amoxicillin & 0.25 & 0.25 & 2 & 16 & $0(0 \%)$ & $0(0 \%)$ & 1.00 \\
\hline Cefuroxim & $\geq 256$ & $\geq 256$ & - & - & NA & NA & NA \\
\hline Clindamycin & 2 & 2 & $\geq 256$ & 8 & $3(6 \%)$ & $1(2 \%)$ & 0.30 \\
\hline Erythromycin & $\geq 256$ & $\geq 256$ & $\geq 256$ & 8 & $29(59 \%)$ & $38(76 \%)$ & 0.07 \\
\hline Ciprofloxacin & $\geq 32$ & $\geq 32$ & $\geq 32$ & 8 & $46(94 \%)$ & $48(96 \%)$ & 0.044 \\
\hline Moxifloxacin & 8 & 8 & $\geq 64$ & 8 & $8(16 \%)$ & $8(16 \%)$ & 0.067 \\
\hline Tetracycline & 8 & 8 & 8 & 16 & $0(0 \%)$ & $0(0 \%)$ & 1.00 \\
\hline Imipenem & $\geq 32$ & $\geq 32$ & 8 & 16 & 14 (29\%) & 25 (50\%) & 0.03 \\
\hline
\end{tabular}

a ECOFF: Epidemiological cut-off value - The European Committee on Antimicrobial Susceptibility Testing (EUCAST).

b CLSI: Clinical and Laboratory Standards Institute.

NA: not applicable. This is stated because no breakpoint was determined by the CLSI and, therefore, the percentage of resistant isolates could not be determined. 
Table $\mathbf{2}$ Mechanisms of resistance found in C. difficile type $\mathbf{0 7 8}$ isolates

\begin{tabular}{llll}
\hline Antibiotic & Origin of isolate ${ }^{\text {a }}$ (total number) & Mechanism of resistance & N. of positive isolates (\%) \\
\hline Tetracycline & Human (6) & $\operatorname{tet(M)}$ & $6(100 \%)$ \\
& Porcine (8) & erm(B) & $3(100 \%)$ \\
Erythromycin & Human (29) & erm(B) & $0(0 \%)$ \\
& Porcine (38) & & $3(100 \%)$ \\
Clindamycin & Human (3) & Aminoacid substitution in GyrA & $0(0 \%)$ \\
& Porcine (1) & & $8(100 \%)$ \\
Moxifloxacin & Human (8) & & $4(57 \%)$
\end{tabular}

a: All isolates with tetracycline MIC $\geq 8 \mathrm{mg} / \mathrm{L}(\mathrm{n}=14)$, erythromycin MIC $\geq 4 \mathrm{mg} / \mathrm{L}(\mathrm{n}=67)$ or clindamycin MIC $\geq 4 \mathrm{mg} / \mathrm{L}$ ( $=4$ ) were analysed for resistance mechanisms. Seven of eight porcine isolates with moxifloxacin MIC $\geq 4 \mathrm{mg} / \mathrm{L}$ were tested for mutations.

farms had not. At farms where diarrhea was present only diarrheal piglets were sampled; at farms without diarrhea, piglets without signs of disease were sampled. At every farm, faecal samples were taken from piglets from at least three different litters. In total, 262 porcine faecal samples were cultured as described previously [9]. DNA was isolated from single $C$. difficile colonies using the QIA amp DNA mini blood kit (QIAgen) according manufacturer's protocol. All isolates were confirmed as $C$. difficile by an in-house developed PCR specific for $C$. difficile glutamate dehydrogenase gene (GluD) and typed as previously described by Bidet et al. [7] and Paltansing et al. [23]. Out of 139 type 078 isolates, per farm two $C$. difficile type 078 isolates were selected (random), except for one farm where three isolates were selected and one farm where one isolate was selected. Piglets were one to seven days old. Forty-nine human type 078 isolates were selected from all samples submitted to the Dutch national reference laboratory (mainly nosocomial diarrhea) between June 2006 and May 2009. To avoid enhanced selection of epidemic strains, only one strain per month per hospital was included.

Antimicrobial susceptibility and mechanisms of resistance C. difficile was cultured in Brain Heart Infusion (BHI) broth for 24 hours at $37^{\circ} \mathrm{C}$ in anaerobic conditions. Subsequently, cultures were diluted to a 1.0 McFarland standard and swabbed on Brucella blood agar plates, supplemented with haemin $5 \mathrm{mg} / \mathrm{L}$ and vitamin $\mathrm{K} 11 \mathrm{mg} / \mathrm{L}$, E-test strips (AB BioMérieux) were applied for tetracycline, amoxicillin, erythromycin, clindamycin, moxifloxacin, imipemen, cefuroxim, and ciprofloxacin. Minimal inhibitory concentrations (MICs) were determined after 48 hours incubation. Antimicrobial susceptibility patterns of human and piglet origin were compared to antimicrobial susceptibility patterns of wild-type $C$. difficile isolates, as recently determined by the European Committee on Antimicrobial Susceptibility Testing (EUCAST) [14]. To classify strains as resistant or susceptible, Clinical and Laboratory Standards Institute (CLSI) breakpoints were used [15].

The mechanisms of resistance to tetracycline, erythromycin, clindamycin and moxifloxacin were investigated in more detail. Tetracycline isolates with $\mathrm{MIC} \geq 8 \mathrm{mg} / \mathrm{L}$ were tested for the presence of tet(M), int and thdX genes according to previous publications by Spigaglia et al. [16], [17]. The last two genes were used as markers for Tn916 and Tn5397-related elements, respectively. Erythromycin and clindamycin isolates with a $\mathrm{MIC} \geq 4 \mathrm{mg} / \mathrm{L}$ were tested for the presence of the $\operatorname{erm}(\mathrm{B})$ gene and moxifloxacin isolates with an $\mathrm{MIC} \geq 4 \mathrm{mg} / \mathrm{L}$ were tested for mutations in the $\operatorname{gyr}(\mathrm{A})$ and $\operatorname{gyr}(\mathrm{B})$ genes according to previously described methods by Spigaglia et al. $[18,19]$.

\section{Clinical data collection and statistical analysis}

At every farm the use of antimicrobials of the sampled piglets was noted since their birth. Information on the antibiotic treatment of the patients in the three months prior to the start of the diarrhea was collected at time of diagnosis. This was done by contacting the physician in charge and consulting patient records. Data were processed using SPAW statistical software for Windows, version 17.0. For comparison of binary data, the Chi-square test was used. If the expected cell count in the contingency table was less than five, the Fisher's exact test was used.

\section{Results}

C. difficile type 078 was detected at all 25 farms (with and without diarrhoeal problems). Fifty porcine 078 isolates and 49 human isolates were selected and included in the study.

Antimicrobial susceptibility and mechanisms of resistance Both human and porcine isolates had susceptibility patterns comparable to other PCR-ribotypes in Europe (grey bars in Figure 1). As shown in Table 1, MIC 90 values were also equal or lower than found in the EUCAST MIC distribution and similar antimicrobial susceptibility patterns 
were observed in human and porcine type 078 isolates for the antimicrobials tested. The majority of isolates were susceptible to amoxicillin (100\%), tetracycline (100\%) and clindamycin (96\%). Interestingly, only $16 \%$ of the isolates were resistant to moxifloxacin. Variable resistance percentage was observed for erythromycin $(76 \%$ in human and $59 \%$ in porcine isolates) and imipenem (29\% in human and $50 \%$ in porcine isolates). High MIC values were observed for ciprofloxacin (94\% resistant) and cefuroxim. In total 14 human and 18 porcine isolates were resistant to four antimicrobials, while 5 porcine isolates were resistant to five antimicrobials (data not shown).

Of the 67 isolates resistant to erythromycin only four isolates $(6 \%)$ were resistant to clindamycin, whereas all clindamycin resistant isolates were resistant to erythromycin (data not shown). The 16 isolates resistant to moxifloxacin were also resistant to ciprofloxacin (data not shown).

Six human isolates and eight porcine isolates with MIC values ranging from 8 to $12 \mathrm{mg} / \mathrm{L}$ and considered susceptible, since the breakpoint for tetracycline is $\geq 16 \mathrm{mg} / \mathrm{L}$, contained a tet $(\mathrm{M})$ gene and a Tn916-like element (Table 2). Among the isolates resistant to erythromycin, only three from human (MIC $\geq 256 \mathrm{mg} / \mathrm{L}$ ) had an $\operatorname{erm}(\mathrm{B})$ gene. These isolates were also high-level resistant to clindamycin (MIC $\geq 256 \mathrm{mg} / \mathrm{L}$ ). The erm(B) gene was not found in a porcine isolate with resistance to both erythromycin and clindamycin. Four of the seven porcine isolates (57\%; one porcine isolate was not tested) and all the human isolates $(100 \%)$ resistant to moxifloxacin had the amino acid substitution Thr82 to Ile in GyrA.

\section{Human and farm specific antimicrobial use}

Human antimicrobial use was known for 34 of 50 patients (68\%). The most frequently used antimicrobial classes were: penicillins $(18 / 34 ; 53 \%)$, cephalosporins (17/34; 50\%) and fluoroquinolones $(9 / 34 ; 26 \%$; mainly ciprofloxacin). As all type 078 isolates had low MIC values for amoxicillin and high MIC values for the cephalosporin cefuroxim, we only investigated the concomitant use of quinolones and the resistance to moxifloxacin. The use of fluoroquinolones (mainly ciprofloxacin) was significantly associated with resistance to moxifloxacin (4/5 patients with prior fluoroquinolone use were resistant, versus $0 / 24$ without fluoroquinolone treatment; $\mathrm{p}<0.01)$. The use of fluoroquinolones was not associated with resistance to ciprofloxacin, as virtually all isolates (94\%) were resistant.

Penicillins (7/25 farms), the $3^{\text {rd }}$ generation fluoroquinolone enrofloxacin (6/25 farms) and colistine (4/25 farms) were commonly used in piglets in this study. At the three farms with no history of diarrhea, no antimicrobials were given to the sampled piglets. Similar to humans, the use of enrofloxacin was significantly associated with resistance to moxifloxacin, which was found in 5 of the 12 piglets treated with enrofloxaxin, and in 3 of the 36 piglets not treated with a fluorquinolone $(\mathrm{p}=0.017)$. One farm was excluded from this analysis because no information on the use of antimicrobials was available for this farm.

\section{Discussion}

We tested $C$. difficile type 078 isolates from humans and piglets for their minimal inhibitory concentration against eight antimicrobial agents and the results were evaluated using the wild type distribution data of EUCAST and the breakpoint values recommended by CLSI. In general, the results obtained indicate that type 078 isolates have similar antimicrobial susceptibility profiles as other PCR-ribotypes, though moxifloxacin resistance was found somewhat less in the examined strains, since only $16 \%$ of them were resistant to this antibiotic. Thirty seven percent of the isolates were resistant to four or more antimicrobials, a percentage comparable to those already described for other C. difficile types [20].

A study concerning type specific risk factors for human CDI in The Netherlands found that prior use of fluoroquinolones (mainly ciprofloxacin) was associated with CDI due type 078 [6]. Of type 078 isolates included is this study, 94\% was resistant to ciprofloxacin (second generation fluoroquinolone), but moxifloxacin (third generation) resistance was low, which is in concordance with the low resistance (27\%) found by Salomon et al., (2011). During the rapid emergence of type 027 a decade ago, resistance of type 027 against moxifloxacin was frequent [21], which was also in line with the association of type 027 and fluoroquinolones in epidemiological studies. Moxifloxacin is not among the most frequently used human fluoroquinolones and is not available for veterinary use. It was however possible to establish an epidemiological link between resistance to moxifloxacin and the administration of fluoroquinolones in general (moxifloxacin and others $)$ in human patients $(\mathrm{p}<0.01)$ and piglets $(\mathrm{p}=0.02)$. Since resistance can be linked with treatment with fluoroquinolones, but resistance is infrequent compared to other PCR-ribotypes isolated from human disease (Figure 1), we doubt that increased fluoroquinolone use alone explains the recent emergence of $C$. difficile type 078 in humans. In piglets, however, type 078 is virtually the only PCR ribotype that causes disease, indicating that a species border exists. The resistance against fluoroquinolones could have contributed to emergence of Type 078 in pigs after the introduction of type 078 in pig farms and the subsequent spread of type 078, as fluoroquinolone use was present in many pig farms and no other $C$. difficile PCR ribotypes were found.

In the Netherlands, there is a remarkable difference in antimicrobial use in humans versus animals. The use of antimicrobials in human medicine in the Netherlands is among the lowest in the European Union, while veterinary 
use of antimicrobials is among the highest [22,23]. The most frequent used antibiotics for all types of disease in sows and suckling piglets are tetracyclines, followed by trimethoprim/sulfonamides (co-trimoxazole) and penicillins [24]. This difference in antimicrobial use was however not reflected in different resistance profiles in our study.

The only discrepancy in human and porcine antimicrobial resistance profile was found for imipenem, with resistance in $29 \%$ of the human isolates and in $50 \%$ of the porcine isolates. Since imipenem is not used in porcine medicine, a higher level of resistance to this antimicrobial in porcine isolates compared to human isolates was unexpected. In the United states where imipenem is neither used in porcine medicine $100 \%$ of piglet isolates had MIC values of $\geq 16 \mathrm{mg} / \mathrm{L}$ [25]. No explanation for this higher level of resistance can be found. Cross-resistance with other antibiotics has not been described for imipenem in gram-positive bacteria. Besides considerable overlap in susceptibility profiles, human and porcine 078 strains also had great genetic similarity when evaluated by multilocus variable-number tandem repeat analysis (MLVA), wholegenome analysis and pulsed-field gel electrophoresis (PFGE) [7,26-28]. Using these methods, numerous human and porcine type 078 isolates were indistinguishable and were therefore suggested to have a high-level of genetic relatedness. Together with the increasing incidence of type 078, the association with community-associated CDI and the presence of type 078 in more than $90 \%$ of the piglets with colonization with $C$. difficile, the hypothesis arose that human and piglet type 078 had a common origin. The results of our study contribute to this hypothesis since resistance patterns highly overlapped despite different antimicrobial pressure [29]. However, as many resistance genes are situated on transposons, antimicrobial susceptibility studies cannot give definitive insight in the (possible) common source of human and porcine CDI.

In this study, resistance to moxifloxacin was associated with the aminoacid substitution Thr82 to Ile in GyrA, as already observed in the majority of European C. difficile clinical isolates resistant to fluoroquinolones [19,30,31]. Surprisingly, no tetracycline resistant isolates were found in our study. However, MIC values between 8 and $12 \mathrm{mg} /$ $\mathrm{L}$ were observed in less than $20 \%$ of the isolates analysed. It has been shown that $C$. difficile strains with reduced susceptibility to tetracycline often carry a tet $(\mathrm{M})$ gene and are inducibly resistant when exposed to sub-inhibitory concentrations of this antibiotic [32]. A recent Irish study found that $M L S_{B}$ resistance in type 078 is less frequently associated with $\operatorname{erm}(\mathrm{B})$ than other types [21]. Our results support this observation since only a minority of the erythromycin resistance (up to 10\%) can be explained by the presence of an $\operatorname{erm}(\mathrm{B})$ gene. Anyway, we did not observe any clindamycin resistant, erythromycin susceptible 078 isolate, as reported in the study mentioned above.
What causes the resistance to erythromycin in 078 isolates is currently unknown. Although other erm(B) negative anaerobes possess one of the other erm genes (frequently erm classes A, F or Q) or overexpress an efflux pump, these have not been determined in C. difficile type 078 [21].

The strengths of our study in comparison with other reports on antimicrobial susceptibility data of $C$. difficile type 078 are that a large number of isolates of different origin were included and eight different antimicrobials were tested $[6,7,25,33]$. Additionally, we compared the antimicrobial susceptibility data with previous antimicrobial treatments of patients and piglets. Limitations of the study are the lack of more detailed data on previous antimicrobial use (preferably expressed as daily defined dosages) and the fact that iinformation in piglets was obtained by interviewing the farmer, which enables reporting bias. Currently, attempts are underway to use defined daily dosage (DDD) as a measure for antimicrobial use, applicable for both humans and animals.

\section{Conclusion}

The results of our study contribute to the hypothesis that human and piglet type 078 have a common origin, since similar antimicrobial susceptibility patterns were found for the antimicrobials tested in human and porcine type 078 isolates, despite a different antimicrobial pressure in humans and pigs. The use of fluoroquinolones was significantly associated with resistance to moxifloxacin in both human and porcine isolates. It is possible that after the introduction of $C$. difficile PCR-ribotype 078 in pig farms, fluoroquinolones contributed to its rapid spread.

\section{Competing interests}

The authors declare that they have no competing interests.

\section{Authors' contribution}

$\mathrm{EK}, \mathrm{MH}$ and IS preformed the antimicrobial resistance testing. EK and $\mathrm{MH}$ additionally collected the samples and the clinical data, furthermore, they wrote the first draft of the manuscript. FB and PS performed tests concerning the mechanism of resistance and revised drafts of the manuscript. LL and EK designed the study and revised drafts of the manuscript. All authors read and approved the final manuscript.

\section{Author details}

'Department of Medical Microbiology, Leiden University Medical Center, PO Box 9600, Leiden 2300 RC, the Netherlands. ${ }^{2}$ Institute for Risk Assessment Sciences, Utrecht University, PO Box 80175, Utrecht 3508 TD, the Netherlands. ${ }^{3}$ Department of Infectious, Parasitic and Immune-mediated Diseases, Instituto Superiore di Sanita', Rome, Italy.

Received: 3 December 2012 Accepted: 29 March 2013

Published: 8 April 2013

\section{References}

1. Loo VG, Poirier L, Miller MA, Oughton M, Libman MD, Michaud S, Bourgault A, Nguyen T, Frenette C, Kelly M, Vibien A, Brassard P, Fenn S, Dewar K, Hudson TJ, Horn R, René P, Monczak Y, Dascal A: A predominantly clonal multi-institutional outbreak of clostridium difficile-associated diarrhea with high morbidity and mortality. N Engl J Med 2005, 353:2442-2449. http://dx.doi.org/10.1056/NEJMoa051639. 
2. McDonald LC, Killgore GE, Thompson A, Owens RC, Kazakova SV, Sambol SP, Johnson S, Gerding DN: An epidemic, toxin gene-variant strain of clostridium difficile. N Engl J Med 2005, 353:2433-2441. http://dx.doi.org/10.1056/NEJMoa051590.

3. Muto CA, Pokrywka M, Shutt K, Mendelsohn AB, Nouri K, Posey K, Roberts T, Croyle K, Krystofiak S, Patel--Brown S, Pasculle AW, Paterson DL, Saul M, Harrison LH: A large outbreak of clostridium difficile--associated disease with an unexpected proportion of deaths and colectomies at a teaching hospital following increased fluoroquinolone Use • Infect Control Hosp Epidemiol 2005, 26:273-280. http://dx.doi.org/10.1086/502539.

4. Hensgens MP, Goorhuis A, Notermans DW, van Benthem BH, Kuijper EJ: Decrease of hypervirulent Clostridium difficile PCR ribotype 027 in the Netherlands. Euro Surveill 2009, 14:19402.

5. Bauer, M. P., D. W. Notermans, B. H. van Benthem, J. S. Brazier, M. H. Wilcox, M. Rupnik, D. L. Monnet, J. T. van Dissel, E. J. Kuijper, and ECDIS Study Group: Clostridium difficile infection in Europe: a hospital-based survey. Lancet 2011, 377:63-73. doi:10.1016/S0140-6736(10)61266-4.

6. Goorhuis A, Bakker D, Corver J, Debast SB, Harmanus C, Notermans DW, Bergwerff AA, Dekker FW, Kuijper EJ: Emergence of Clostridium difficile infection due to a new hypervirulent strain, polymerase chain reaction ribotype 078. Clin Infect Dis 2008, 47:1162-1170. doi:10.1086/592257.

7. Debast SB, van Leengoed LA, Goorhuis A, Harmanus C, Kuijper EJ, Bergwerff $A A$ : Clostridium difficile $P C R$ ribotype 078 toxinotype $V$ found in diarrhoeal pigs identical to isolates from affected humans. Environ Microbiol 2009, 11:505-511. doi:10.1111/j.1462-2920.2008.01790.x.

8. Keel K, Brazier JS, Post KW, Weese S, Songer JG: Prevalence of PCR Ribotypes among Clostridium difficile Isolates from Pigs, Calves, and Other Species ${ }^{\nabla}$. J Clin Microbiol 2007, 45:1963-1964.

9. Keessen EC, Hopman NE, van Leengoed LA, van Asten AJ, Hermanus C, Kuijper EJ, Lipman LJ: Evaluation of four different diagnostic tests to detect Clostridium difficile in piglets. J Clin Microbiol 2011, 49:1816-1821. doi:10.1128/JCM.00242-11.

10. Songer JG, Anderson MA: Clostridium difficile: an important pathogen of food animals. Anaerobe 2006, 12:1-4. doi:10.1016/j.anaerobe.2005.09.001

11. Songer JG: The emergence of Clostridium difficile as a pathogen of food animals. Anim Health Res Rev 2004, 5:321-326.

12. Anderson MA, Songer JG: Evaluation of two enzyme immunoassays for detection of Clostridium difficile toxins $A$ and $B$ in swine. Vet Microbiol 2008, 128:204-206.

13. Bartlett JG, Gerding DN: Clinical recognition and diagnosis of Clostridium difficile infection. Clin Infect Dis 2008, 46(Suppl 1):S12-8. doi:10.1086/ 521863.

14. Anonymous, Eucast2. 2011. http://217.70.33.99/Eucast2/SearchController/ search.jsp?action $=$ performSearch\&Begin $\mid$ dex $=0 \&$ Micdif $=$ mic\&Numberlndex $=50 \& A n t i b=-1 \&$ Specium $=222$

15. Hecht DW, Citron DM, Dzink-Fox J, Gregory WW, Jacobus NV, Jenkins SG, Rosenblatt JE, Schuetz AN, Wexler H: Methods for antimicrobial susceptibility testing of anaerobic bacteria; approved standard - eighth edition. 2012, 32:M11-A8.

16. Spigaglia P, Mastrantonio P: Molecular analysis of the pathogenicity locus and polymorphism in the putative negative regulator of toxin production (TcdC) among Clostridium difficile clinical isolates. J Clin Microbiol 2002, 40:3470-3475.

17. Spigaglia P, Barbanti F, Mastrantonio P: Detection of a genetic linkage between genes coding for resistance to tetracycline and erythromycin in Clostridium difficile. Microb Drug Resist 2007, 13:90-95. doi:10.1089/ mdr.2007.723.

18. Spigaglia P, Mastrantonio P: Comparative analysis of Clostridium difficile clinical isolates belonging to different genetic lineages and time periods. J Med Microbiol 2004, 53:1129-1136.

19. Spigaglia P, Barbanti F, Louie T, Barbut F, Mastrantonio P: Molecular analysis of the gyrA and gyrB quinolone resistance-determining regions of fluoroquinolone-resistant Clostridium difficile mutants selected in vitro. Antimicrob Agents Chemother 2009, 53:2463-2468. doi:10.1128/ AAC.01252-08

20. Spigaglia, P., F. Barbanti, P. Mastrantonio, and European Study Group on Clostridium difficile (ESGCD): Multidrug resistance in European Clostridium difficile clinical isolates. J Antimicrob Chemother 2011, 66:2227-2234. doi:10.1093/jac/dkr292.

21. Solomon K, Fanning S, McDermott S, Murray S, Scott L, Martin A, Skally M, Burns K, Kuijper E, Fitzpatrick F, Fenelon L, Kyne L: PCR ribotype prevalence and molecular basis of macrolide-lincosamide-streptogramin B (MLSB) and fluoroquinolone resistance in Irish clinical Clostridium difficile isolates. J Antimicrob Chemother 2011, 66:1976-1982. doi:10.1093/jac/dkr275.

22. Grave K, Torren-Edo J, Mackay D: Comparison of the sales of veterinary antibacterial agents between 10 European countries. J Antimicrob Chemother 2010, 65:2037-2040. doi:10.1093/jac/dkq247.

23. Coenen S, Adriaenssens N, Versporten A, Muller A, Minalu G, Faes C, Vankerckhoven V, Aerts M, Hens N, Molenberghs G, Goossens H, Project Group ESAC: European Surveillance of Antimicrobial Consumption (ESAC): outpatient use of tetracyclines, sulphonamides and trimethoprim, and other antibacterials in Europe (1997-2009). J Antimicrob Chemother 2011, 66(Suppl 6):vi57-70. doi:10.1093/jac/dkr458.

24. Anonymous Antibiotic use - Wageningen UR - LEl. 2011. http://www.maran.wur.nl/.

25. Norman KN, Harvey RB, Scott HM, Hume ME, Andrews K, Brawley AD: Varied prevalence of Clostridium difficile in an integrated swine operation. Anaerobe 2009, 15:256-260. doi:10.1016/j.anaerobe.2009.09.006.

26. Bakker D, Corver J, Harmanus C, Goorhuis A, Keessen EC, Fawley WN, Wilcox $\mathrm{MH}$, Kuijper EJ: Relatedness of human and animal Clostridium difficile PCR ribotype 078 isolates determined on the basis of multilocus variable-number tandem-repeat analysis and tetracycline resistance. J Clin Microbiol 2010, 48:3744-3749. doi:10.1128/JCM.01171-10.

27. Jhung MA, Thompson AD, Killgore GE, Zukowski WE, Songer G, Warny M, Johnson S, Gerding DN, McDonald LC, Limbago BM: Toxinotype V Clostridium difficile in humans and food animals. Emerg Infect Dis 2008, 14:1039-1045

28. Stabler RA, Gerding DN, Songer JG, Drudy D, Brazier JS, Trinh HT, Witney AA Hinds J, Wren BW: Comparative phylogenomics of Clostridium difficile reveals clade specificity and microevolution of hypervirulent strains. J Bacteriol 2006, 188:7297-7305. doi:10.1128/JB.00664-06.

29. Hunter PA, Dawson S, French GL, Goossens H, Hawkey PM, Kuijper EJ, Nathwani D, Taylor DJ, Teale CJ, Warren RE, Wilcox MH, Woodford N, Wulf MW, Piddock LJ: Antimicrobial-resistant pathogens in animals and man: prescribing, practices and policies. J Antimicrob Chemother 2010, 65(Suppl 1):i3-17. doi:10.1093/jac/dkp433.

30. Spigaglia P, Barbanti F, Mastrantonio P, Brazier JS, Barbut F, Delmee M, Kuijper E, Poxton IR, European Study Group on Clostridium difficile (ESGCD): Fluoroquinolone resistance in Clostridium difficile isolates from a prospective study of C. difficile infections in Europe. J Med Microbiol 2008, 57:784-789. doi:10.1099/jmm.0.47738-0.

31. Drudy D, Kyne L, O'Mahony R, Fanning S: gyrA mutations in fluoroquinolone-resistant Clostridium difficile PCR-027. Emerg Infect Dis 2007, 13:504-505.

32. Spigaglia $P$, Barbanti $F$, Mastrantonio $P$ : New variants of the tet(M) gene in Clostridium difficile clinical isolates harbouring Tn916-like elements. J Antimicrob Chemother 2006, 57:1205-1209. doi:10.1093/jac/dkl105.

33. Post KW, Songer JG: Antimicrobial susceptibility of Clostridium difficile isolated from neonatal pigs with enteritis. Anaerobe 2004, 10:47-50. doi:10.1016/j.anaerobe.2004.01.003.

doi:10.1186/2047-2994-2-14

Cite this article as: Keessen et al:: Antimicrobial susceptibility profiles of human and piglet Clostridium difficile PCR-ribotype 078. Antimicrobial Resistance and Infection Control

\section{Submit your next manuscript to BioMed Central and take full advantage of:}

- Convenient online submission

- Thorough peer review

- No space constraints or color figure charges

- Immediate publication on acceptance

- Inclusion in PubMed, CAS, Scopus and Google Scholar

- Research which is freely available for redistribution 